\title{
Incidencia de Necrosis Pulpar con y sin rarefacción apical según sexo, edad y localización
}

Incidence of pulpar necrosis with and without rarefaction apical according to sex, age and localization.
A incidência de polpa e necrose apical rarefaçāo por sexo, idade e localização
Fecha de Recepción 22 de agosto de 2012
Aceptado parra su publicación 04 de octubre de 2012

\section{Natalia Belén Montiel}

Becaria de Posgrado Iniciación en la investigación, tipo A, de la Secretaría General de Ciencia y

Técnica de la Universidad Nacional del Nordeste.

E-mail: natyodonto2007@yahoo.com.ar

Susana Beatriz Finten de Tarallo

Profesora Titular Cátedra de Endodoncia

Facultad de Odontología de la Universidad

Nacional del Nordeste

E-mail: susanafinten@yahoo.com.ar

Lugar deTrabajo

Facultad de Odontología

Universidad Nacional del Nordeste.

Avenida Libertad 5450. Corrientes (Argentina). Código Postal: 3400.

TEl fox: 3794-457992.

\section{Resumen}

El tejido pulpar es afectado por diferentes tipos de irritantes que cuando actúan con cierta intensidad provocarán un daño irreversible que llevará poco a poco a la degeneración ocasionando una necrosis pulpar, la cual representa una condición para la proliferación bacteriana, pudiendo ésta extenderse hacia el periápice, provocando reacciones periapicales que podrán ser observadas radiográficamente desde un ligero espesamiento a zonas radiolúcidas bien delimitadas o con bordes difusos. Sin embargo, en ocasiones, a pesar de tener una pulpa necrosada no se observa ningún tipo de alteración radiográfica a nivel periapical, por lo tanto se pueden diferenciar piezas dentarias con diagnóstico de necrosis pulpar con presencia o ausencia de lesiones periapicales observadas radiográficamente. El objetivo de este trabajo fue determinar la incidencia de casos con necrosis pulpar con y sin rarefacción apical, según sexo, edad y localización de las piezas dentarias a las que se les realizó tratamiento de conducto en el período de 2005 al 2007. Al analizar las variables anteriormente citadas, se pudo comprobar que existe una incidencia de casos de necrosis pulpar sin rarefacción apical en un porcentaje ligeramente mayor respecto a los casos que mostraron rarefacción apical. En ambas situaciones estuvieron más afectadas las mujeres que los hombres con una incidencia significativa en las edades comprendidas de 13 a 30 años, siendo en el incisivo central superior la localización más frecuente para ambos sexos. Se pudo comprobar mediante la prueba del Chi 
Cuadrado que hubo relación estadísticamente significativa $(p<0.05)$ en cuanto a la localización de la afección, diagnóstico y sexo.

\section{Palabras Claves}

Necrosis pulpar, rarefacciones apicales, sexo, edad, localización.

\section{Abstract}

The pulp tissue is affected by different types of irritants that when they act with a certain intensity will cause irreversible damage that will lead gradually to the degeneration causing pulp necrosis, which represents a condition for bacterial growth, it may extend into the periapical, causing periapical reactions that may be observed radiographically from a slight thickening of well-defined radiolucent areas or diffuse edges. But sometimes, despite having a necrotic pulp was not observed any alteration periapical radiographic level, therefore can be differentiated teeth with a diagnosis of pulpal necrosis with presence or absence of periapical lesions radiographically. The aim of this study was to determine the incidence of teeth with pulp necrosis and apical rarefaction by sex, age and location. When analyzing the variables listed above, we noted that there is an incidence of pulp necrosis with apical rarefaction in a slightly higher percentage with respect to cases that showed apical rarefaction. In both situations, women were more affected than men with a significant impact on the ages of 13 to 30 years, and also the most frequent location was in the upper central incisor in both sexes. Demonstrated by the Chi square test was statistically significant $(p<0.05)$ as to the location of the condition, diagnosis and gender.

Key words

Pulp necrosis, rarefaction apical, sex, age, location.

\section{Resumo}

O tecido pulpar é afetada por diferentes tipos de substâncias irritantes que, quando agem com uma certa intensidade causará dano irreversível que levará gradualmente à degeneração causando necrose pulpar, o que representa uma condição para o crescimento bacteriano, pode se estender para o periapicais, causando reações periapicais que podem ser observadas radiograficamente de um ligeiro espessamento do bem definidas áreas radiolúcidas ou bordas difusas. Mas às vezes, apesar de ter uma polpa necrótica não foi observada qualquer alteração radiográficas periapicais nível, portanto, podem ser diferenciados os dentes com um diagnóstico de necrose pulpar com a presença ou ausência de lesões periapicais radiograficamente. $O$ objetivo deste estudo foi determinar a incidência de dentes com necrose pulpar com e sem apical rarefação por sexo, idade e localização. Ao analisar as variáveis acima, observamos que existe uma incidência de necrose polpa com rarefação apical em uma percentagem ligeiramente superior no que diz respeito aos casos que apresentaram rarefação apical. Em ambas as situações, as mulheres foram mais afetadas que os homens com um impacto significativo sobre as idades de 13 a 30 anos, e também a localização mais freqüente foi na incisivos centrais superiores em ambos os sexos. Demonstrado pelo teste Chi quadrado foi estatisticamente significativa ( $P$ $<0,05)$ quanto à localização da doença, diagnóstico e sexo.

\section{Palavras chave}

Necrose pulpar, rarefação apical, sexo, idade e localização.

\section{Introducción}

La inflamación periapical representa una respuesta biológica de defensa natural que tiene como responsables a varios agentes etiológicos (microbianos, químicos, físicos, otros) que producen la inflamación pulpar. De acuerdo al grado de virulencia de los microorganismos y a la índole de las defensas orgánicas se establecen diversos tipos de alteraciones pulpo-periapicales. Cuando la pulpa dentaria se ha dañado irreversiblemente, degenerará poco a poco y ocasionará necrosis que por lo general ocurre con lentitud y sin síntomas espectaculares'.

La necrosis pulpar es la muerte de la pulpa. Es la evolución de una pulpitis irreversible no tratada, una lesión traumática o cualquier circunstancia que origine interrupción prolongada del suministro de sangre a la pulpa. La necrosis pulpar puede ser total o parcial, esta última es más factible en dientes multirradiculares ${ }^{2}$. 
Cuando se produce una necrosis pulpar, los productos metabólicos de la degeneración pulpar o toxinas bacterianas pueden avanzar hacia el periápice a través del sistema de conductos radiculares, provocando la desmineralización de la lámina ósea cortical ${ }^{3}$.

El conducto radicular con una pulpa necrótica se transforma en ambiente propicio a la proliferación bacteriana, por la presencia de nutrientes y de restos orgánicos provenientes de los subproductos bacterianos y del propio tejido necrótico, que sirve de sustrato o medio de cultivo a esas bacterias, así también la $\mathbf{t}^{\circ}$ corporal de $37^{\circ} \mathrm{C}$ favorable para la reproducción. En esas condiciones los microorganismos proliferan al abrigo de los elementos naturales de defensa del organismo, que en ese momento se encuentran concentrados en el periápice. Surgen así las reacciones periapicales que varían en intensidad. Si hiciéramos un análisis histológico de las piezas dentarias seguramente se observaría además de la presencia de inflamación, un área de reabsorción ósea que puede afectar a la cortical ósea vestibular o lingual, mostrar también una erosión de cemento apical y una exposición de dentina denudada y contaminada al ambiente periapical. El diagnóstico radiográfico de la zona periapical puede ser normal ${ }^{4}$ aún a pesar que exista una inflamación periapical, pues todavía no se ha perdido la integridad de los tejidos duros (hueso, cemento, dentina) 5 . En la necrosis no tratada puede observarse ligamento periodontal engrosado ${ }^{4}$.

Es decir el primer cambio periapical apreciable radiográficamente es el ensanchamiento del ligamento periodontal por reabsorción de la cortical del fondo del alvéolo y por extrusión del diente como consecuencia de la inflamación. Si el proceso continúa su avance, habrá una destrucción de los tejidos periapicales y radiográficamente se observará la interrupción de la continuidad del espacio del ligamento y de la lámina dura y la aparición de una imagen radiolúcida de características variables. La destrucción o la continuidad de la lamina dura alrededor del ápice son consideradas esenciales para el diagnóstico de enfermedad periapical inicial, así como el ensanchamiento del espacio periodontal en la misma área ${ }^{3}$.

Se entiende por dientes portadores de lesiones periapicales los que al examen radiográfico exhiben un área de rarefacción periapical. El volu- men de esta área puede ser muy variable; puede aparecer desde un simple espesamiento del ligamento periodontal hasta algunos milímetros de diámetro, y se admite como lesión periapical grande aquella que presenta un diámetro por encima de $5 \mathrm{~mm}^{6}$.

Existen muchas condiciones patológicas que afectan a los maxilares, estas se presentan radiográficamente como áreas radiolúcidas o radiopacas $^{7-3}$

Las lesiones periapicales resultantes de la necrosis pulpar son las condiciones patológicas más comunes del hueso alveolar ${ }^{3}$.

Puesto que por lo general los síntomas clínicos ocurren infrecuentemente $y$ las biopsias periapicales son difíciles de obtener rutinariamente, la incidencia de las alteraciones patológicas en los tejidos periapicales después del tratamiento en su mayor parte estaría determinada por el diagnóstico radiográfico ${ }^{8}$.

El diagnóstico radiográfico puede revelar una zona radiolúcida grande o pequeña, difusa o circunscrita en la zona apical, que varía desde un engrosamiento del ligamento y reabsorción de la lámina dura hasta destrucción del hueso periapical con franca lesión periapical. La inflamación y destrucción son siempre mayores que lo que se observa en las radiografías ${ }^{4}$. Dado que es imposible apreciar en una radiografía una reabsorción que se produce en las superficies vestibulares o linguales de la raíz?.

Las radiografías constituyen un método diagnóstico complementario esencial para detectar lesiones periapicales. Sin embargo, entre las limitaciones de los procedimientos radiográficos convencionales está la imposibilidad de demostrar la presencia y tamaño real de las de las lesiones, tampoco permiten el diagnóstico diferencial entre lesiones quísticas y no quísticas ${ }^{3}$, lo cual solo se podrá diagnosticar con análisis histopatológico.

Existen grandes variaciones entre los estudios clínicos y radiográficos sobre los resultados del tratamiento endodóntico, podrían ser en parte explicadas por las dificultades en definir y mantener los criterios de la evidencia radiográfica de lesión periapical, desde el diagnóstico del espacio ensanchado o grosor periodontal, es por ello que es importante la calibración de los observadores ${ }^{8}$.

Un estudio que ha tenido gran influencia en las 
investigaciones fue el publicado por Strindberg ${ }^{10}$ quién reveló un sistema de criterios basados sobre ausencia o presencia de rarefacciones radiográficas alrededor del ápice del conducto radicular.

La comparación en las respuestas muestran grandes desacuerdos entre observadores, un $21,8 \%$ de las observaciones de los examinadores no acordaron, incluso con sus primeras apreciaciones del mismo caso, al ser evaluadas en segunda instancia".El significado de la variación inter e intraexaminadores ha sido extensamente estudiada en radiografías de diagnóstico de caries por Haugejorden ${ }^{12}$ y Gröndahl ${ }^{13}$, éste concluyó que es evidente que las diferencias entre los estudios epidemiológicos podrían reflejar variaciones extensas entre observadores de la misma manera como diferencias entre la población.

Un cambio radiográfico débil puede causar incertidumbre al observador, además de producir falsos registros negativos, cuando se intenta hacer un diagnostico radiológico.

Para la evaluación de hallazgos periapicales se han establecido tres estrategias de diagnóstico que están actualmente en uso en estudios epidemiológicos e investigaciones. Se refieren a una clasificación basada en el aspecto radiográfico del espacio del ligamento periodontal, el índice periapical y una estricta definición de enfermedad periapical. La decisión de si existe o no lesión periapical puede ser tomada solo después de un cuidadoso análisis del espacio del ligamento periodontal, lámina dura, el patrón trabecular y los espacios medulares ${ }^{3}$.

Es por ello que resulta indispensable establecer una serie de condiciones para la interpretación radiográfica como ser, óptimas condiciones visuales, entender las limitaciones de las imágenes radiográficas, calidad de la imagen a ser interpretada, conocimiento de las estructuras radiográficas normales y patológicas, técnica sistemática que permita observar las radiografías integralmente, interpretar los hallazgos radiográficos, diagnóstico radiográfico diferencial.

Así mismo los bordes de la lesión periapical, pueden definirse como bien definidos o difusos. El borde definido es aquel en el que toda o la mayoría de la periferia de la lesión esta bien delimitada. El borde difuso o indefinido es aquel en el que la periferia de la lesión se encuentra mal delineada ${ }^{7}$.
Las tres características radiográficas más importantes que debemos observar en los tejidos apicales normales son, la línea radiolúcida contínua y fina alrededor de la raíz; que representa el espacio periodontal; la línea radiopaca y fina adyacente a la línea radiolúcida, que representa la lámina dura; el patrón trabecular y la densidad del hueso circundante.

Estas características representan la clave para la interpretación de patologías pulpoperiapicales, cambios desde espesor, continuidad y radiodensidad, reflejan la presencia de cualquier enfermedad subyacente.

El objetivo de este trabajo fue determinar la incidencia de casos de necrosis pulpar con y sin rarefacción apical según sexo, edad y localización y si existe relación significativa entre las variables estudiadas.

\section{Materiales y Métodos}

Del total de 2833 historias clínicas de los pacientes atendidos en la Cátedra de Endodoncia de la Facultad de Odontología de la Universidad Nacional del Nordeste durante el período 2005 al 2007. se seleccionó una muestra de 768 historias clínicas-radiográficas que presentaban el diagnóstico de necrosis pulpar.

Las variables analizadas fueron: sexo, edad, localización de la pieza dentaria afectada y diagnóstico, teniendo en cuenta la presencia de ensanchamiento apical y/o de rarefacción apical .detectadas al exámen radiográfico.

Los datos extraídos de cada historia clínica se tabularon en una planilla diseñada a tal efecto, que permitió ordenar y sistematizar la información. Se excluyeron de este estudio todas las historias clínicas que no se ajustaban a los criterios de inclusión mencionados.

Se determinó el porcentaje de mujeres y varones afectados, el grupo etáreo de mayor incidencia y la relación entre la localización de la afección y el diagnóstico para cada sexo. Para analizar la variable edad se agrupó en rangos etáreos, de 12 a 20 años; de 21 a 30 años; 31 a 50 años y 51 a 75 años. Se identificó la localización de las piezas dentarias con diagnóstico de necrosis pulpar: Incisivo Central, Incisivo Lateral, Canino, primero y segundo Premolar, tanto superiores como inferiores.

Se utilizó la prueba estadística chi cuadrado para 
establecer la relación entre la localización de la afección y el diagnóstico de necrosis pulpar, necrosis pulpar con ensanchamiento periapical y necrosis pulpar con proceso periapical para cada sexo, resultando significativo el valor $\mathrm{p}<0.05$.

La presencia y/o ausencia de ensanchamiento periodontal y/o de rarefacciones apicales se determinó en base al estudio de las radiografías preoperatorias de cada historia clínica que reunían constraste, nitidez e isomorfismoLas radiografías fueron tomadas con los equipos marca Dabi Atlante (made in Brazil) con valores utilizados de $70 \mathrm{kv}, 8 \mathrm{~mA}$; utilizando películas marca Kodak y un tiempo de exposición de 0,8 segundos, utilizandolos elementos de protección según normas vigentes. El procedimiento de revelado fue manual.

Para determinar el diagnóstico de necrosis pulpar con o sin complicación periapical se observaron las películas radiográficas con negatoscopio con lupa incorporada, previa calibración de los observadores, $y$ se tuvo en cuenta la presencia de ensanchamiento periodontal y/o rarefacción apical, determinándose las siguientes categorías: Necrosis pulpar con signos radiográficos periapicales normales: cuando en las radiografías se observaba un espacio radiolúcido uniforme (correspondiente al ligamento periodontal), continuo, siguiendo el contorno de la porción radicular sin ningún tipo de rarefacción y con lámina dura continua, sin interrupción.

Necrosis pulpar con ensanchamiento periapical cuando el espacio del ligamento periodontal, radiolúcido se encontraba ensanchado, con un espesor de entre 0,5 a $2 \mathrm{~mm}$.

Necrosis pulpar con proceso periapical. Cuando se observa una zona radiolúcida, bien circunscripta al periapice, con bordes bien delimitados en algunos casos o difusos en otros, de un tamaño superior a los $2 \mathrm{~mm}$. y con lámina dura discontinua por el proceso inflamatorio instalado.

\section{Resultados}

Se analizaron 2833 historias clínicas de pacientes atendidos por alumnos de la Cátedra de Endodoncia de la Facultad de Odontología de la Universidad Nacional del Nordeste, de las cuales 768 correspondían a diagnóstico de necrosis pulpar; 492 (64\%) correspondieron al sexo femenino y 276 (36\%) al sexo masculino, con la siguiente distribución de rango etáreo de acuerdo al orden de frecuencia; entre 21 y 30 años: 307 (40\%), 195 (25\%) del sexo femenino y II 2 (15\%) del sexo masculino; entre 31 y 50 años: 237 pacientes $(31 \%), 174(23 \%)$ para el sexo femenino y $63(8 \%)$ para el sexo masculino (ver tabla $\mathrm{N}^{\circ} \mathrm{I}$ ).

Tabla $\mathbb{N}^{\circ}$ I: Número y porcentaje de historias clínicas con diagnóstico de necrosis y/o gangrena pulpar según sexo y grupo etario. Cátedra Endodoncia. Facultad de Odontología. Universidad Nacional del Nordeste. Año 2005-2007.

\begin{tabular}{|c|c|c|c|c|}
\hline \multirow{2}{*}{$\begin{array}{c}\text { GRUPOS } \\
\text { ETARIOS }\end{array}$} & \multicolumn{2}{|c|}{ SEXO FEMENINO } & \multicolumn{2}{c|}{ SEXO MASCULINO } \\
\cline { 2 - 5 } $12-20$ & NUMERO & PORCENTAJE & NUMERO & PORCENTAJE \\
\hline $21-30$ & 195 & $13 \%$ & 70 & $9 \%$ \\
\hline $31-50$ & 174 & $25 \%$ & 112 & $15 \%$ \\
\hline $51-75$ & 25 & $23 \%$ & 63 & $8 \%$ \\
\hline TOTAL & 492 & $3 \%$ & 31 & $4 \%$ \\
\hline
\end{tabular}


Gráfico I: Incidencia de diagnóstico de necrosis y/o gangrena pulpar según edades. Cátedra Endodoncia. Facultad de Odontología. Universidad Nacional del Nordeste. Año 2005-2007.

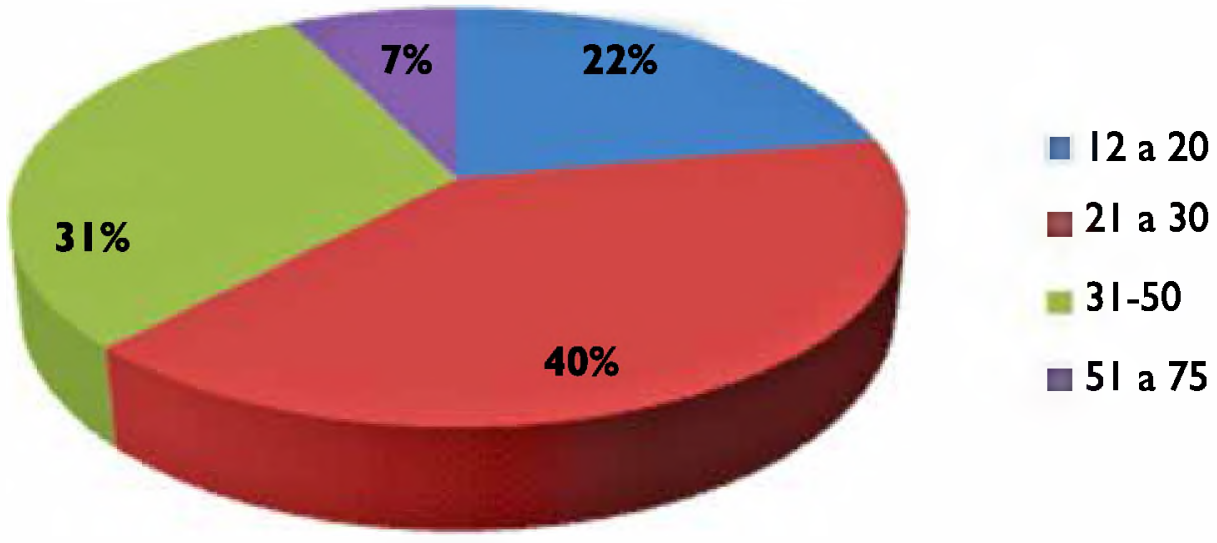

Para el análisis de los resultados se utilizó la Prueba de Chi cuadrado, se evaluó la relación entre la localización de la pieza dentaria y el diagnóstico para cada sexo, dando diferencias estadísticamente significativas como se detallan en las tablas de contingencias $\mathrm{N}^{\circ}$ II y III.

Teniendo en cuenta la cantidad de casos analizados (768), el diagnóstico que más incidencia tuvo en ambos sexos fue el de necrosis y 10 gangrena con signos radiográficos periapicales normales, posteriormente le siguió el diagnóstico de necrosis y lo gangrena con proceso periapical y finalmente el diagnóstico de necrosis y lo gangrena con ensanchamiento periodontal (tablas de contingencias II y III). Los resultados fueron los siguientes: en el sexo femenino 23 I (47\%) de los casos presentaron diagnóstico de necrosis y lo gangrena, 159 (32\%) diagnóstico de necrosis y lo gangrena con proceso periapical y $102(21 \%)$ con diagnóstico de necrosis y $/ 0$ gangrena con ensanchamiento periodontal; en el sexo masculino 117 (42\%) de los casos presentaron diagnóstico de necrosis y /o gangrena, 100 (36\%) diagnóstico de necrosis y lo gangrena con proceso periapical y 59 (2l\%) con diagnóstico de necrosis y/o gangrena con ensanchamiento periodontal.

Según la localización; las piezas dentarias que más incidencia tuvieron (en ambos sexos) fueron: el incisivo central superior, incisivo lateral superior y primer premolar superior (gráficos 2 y 3).

\section{Discusión}

Los resultados obtenidos a partir de la casuística estudiada con respecto al sexo se coincide con otras publicaciones ${ }^{14,8}$, que indican casi el doble de incidencia de atención a mujeres, señalando probablemente la tendencia de un mejor cuidado de su salud y estética.

Similares resultados fueron encontrados en un estudio ${ }^{15}$ cuyo propósito fue analizar los tratamientos endodónticos realizados. Los pacientes con grupo etario entre 20 a 30 años y de 31 a 40 años fueron los de mayor atención tanto en varones como en mujeres, siendo el número de éstas $(23,4 \%)$ ligeramente superior al grupo masculino(22,4\%).

En cuanto a la variable edad se coincidió con otros autores ${ }^{16}$ en que el grupo etario más frecuente fue el comprendido entre 21 y 30 años. Si bien no está estandarizado las edades que comprenden cada uno de los grupos porque algunos dan márgenes entre menores de 20, 21 y 40,41 a 60,60 y más de $60^{17}$ y otros estratifican en intervalos de 20-29, 30-39, mayor o igual a $80^{18}$.

Al relacionar el diagnóstico con la localización (pieza dentaria afectada) se obtuvieron resultados similares ${ }^{14}$, con respecto a que el Incisivo Central superior es la pieza más afectada en primer lugar con diagnóstico de necrosis pulpar sin lesión periapical, luego con diagnóstico de necrosis con proceso periapical y en último término con ensanchamiento periodontal, al comparar con las otras piezas dentarias inclui- 
Tablas de contingencia $N^{\circ}$ II. Sexo Femenino.Frecuencias relativas por filas.

\begin{tabular}{|l|c|c|c|c|}
\hline Localizacion & N y G pulpar & $\begin{array}{c}\text { NyG con } \\
\text { Ensanchamiento }\end{array}$ & NyG c/Proceso & Total \\
\hline I.C SUP & $0,4 I$ & 0,23 & 0,37 & $\mathrm{I}, 00$ \\
\hline I.L SUP & $0,4 I$ & 0,20 & 0,39 & $\mathrm{I}, 00$ \\
\hline C. SUP & 0,65 & 0,24 & $0,1 \mathrm{I}$ & $\mathrm{I}, 00$ \\
\hline I. C INF. & 0,57 & 0,10 & 0,33 & $\mathrm{I}, 00$ \\
\hline I.L. INF & 0,67 & 0,03 & 0,30 & $\mathrm{I}, 00$ \\
\hline C. INF & 0,56 & 0,16 & 0,28 & $\mathrm{I}, 00$ \\
\hline Ier.PM SUP & 0,50 & 0,25 & 0,25 & $\mathrm{I}, 00$ \\
\hline 2do.PM SUP & 0,60 & 0,20 & 0,20 & $\mathrm{I}, 00$ \\
\hline Ier PM INF & 0,25 & 0,25 & 0,50 & $\mathrm{I}, 00$ \\
\hline 2do.PM INN & 0,20 & 0,60 & 0,20 & $\mathrm{I}, 00$ \\
\hline TOTAL & 0,47 & $0,2 \mathrm{I}$ & 0,32 & $\mathrm{I}, 00$ \\
\hline
\end{tabular}

$\begin{array}{llll}\text { Estadistico } & \text { Valor } & \text { gl } & \text { P } \\ \text { Chi Cuadrado Pearson } & 37,4 I & I 8 & 0,0046\end{array}$

Tablas de contingencia $\mathbb{N}^{\circ}$ III. Sexo Masculino Frecuencias relativas por filas.

\begin{tabular}{|l|c|c|c|c|}
\hline Localizacion & Ny G pulpar & $\begin{array}{c}\text { NyG con } \\
\text { Ensanchamiento }\end{array}$ & NyG c/Proceso & Total \\
\hline I.C SUP & 0,38 & 0,19 & 0,43 & $\mathrm{I}, 00$ \\
\hline I.L SUP & 0,26 & 0,22 & 0,52 & $\mathrm{I}, 00$ \\
\hline C. SUP & 0,67 & 0,24 & 0,10 & $\mathrm{I}, 00$ \\
\hline I. C INF. & 0,53 & 0,13 & 0,33 & $\mathrm{I}, 00$ \\
\hline I.L. INF & 0,67 & 0,00 & 0,33 & $\mathrm{I}, 00$ \\
\hline C. INF & 0,47 & 0,18 & 0,35 & $\mathrm{I}, 00$ \\
\hline ler.PM SUP & 0,44 & 0,21 & 0,36 & $\mathrm{I}, 00$ \\
\hline 2do.PM SUP & 0,67 & 0,33 & 0,00 & $\mathrm{I}, 00$ \\
\hline ler PM INF & 0,20 & 0,60 & 0,20 & $\mathrm{I}, 00$ \\
\hline 2do.PM INN & 0,44 & 0,33 & 0,22 & $\mathrm{I}, 00$ \\
\hline TOTAL & 0,42 & 0,21 & 0,36 & $\mathrm{I}, 00$ \\
\hline
\end{tabular}

$\begin{array}{llll}\text { Estadistico } & \text { Valor } & \text { gl } & \text { P } \\ \text { Chi Cuadrado Pearson } & 37,41 & 18 & 0,0046\end{array}$


das en la casuística (incisivos laterales, caninos y premolares superiores e inferiores).

Se hallo discrepancia en los reportes con respecto a la realización de los criterios para realizar la evaluación radiográfica, así, Reit Claes y $\mathrm{cols}^{8}$ consideraron diferentes condiciones periapicales a ser analizadas: normal, incremento del espesor del ligamento periodontal con lámina dura continua, incremento del espesor del ligamento periodontal con lámina dura difusa, radiolucidez periapical y dificultades para la lectura radiográfica.

Según, Lorena Lafuente Taborga ${ }^{19}$ de acuerdo a la edad, en piezas antero-superiores, observó, en pacientes entre los 15 a 40 años, el mayor porcentaje de procesos periapicales presentándose un $61.3 \%$; un $18.4 \%$, se detectó en pacientes entre los 41 á 59 años y con un $7.1 \%$, en pacientes mayores de 60 años. En piezas antero-inferiores, se determinó en pacientes entre los 15 á 40 años un $64.3 \%$, siendo éste el grupo el de mayor riesgo; con un $25 \%$ se encuentran los pacientes entre $4 \mathrm{I}$ á 59 años y en pacientes mayores de 60 años, un 10.7\%. Según el sexo, se reveló que existe un mayor porcentaje de estas patologías periapicales en pacientes mujeres, estableciéndose en un $55.2 \%$ en piezas antero-superiores y un $8.0 \%$ en piezas antero-inferiores. El sexo masculino presenta procesos periapicales: $30.8 \%$ en piezas antero-superiores y un $6.0 \%$, en piezas antero-inferiores.

El aporte del presente trabajo es brindar información sobre la incidencia de la relación entre variables como sexo, edad y localización de la pieza dentaria afectada o no de patología periapical, siguiendo los criterios expresados precedentemente que no siempre coinciden con los seguidos por otros autores, siendo esta una limitación para el análisis.

Consideramos que sería interesante y necesario extender este tipo de estudio al siguiente periodo del 2008 al 2010 para observar si se mantienen los resultados o existen variaciones.

\section{Conclusiones}

- La edad más frecuente de presentación de necrosis y/o gangrena pulpar según los criterios analizados fue la comprendida entre los 21 y 30 años, siendo el sexo femenino el más afectado, casi el doble con respecto al sexo masculino. En los demás grupos etarios analizados ( 12 a 20; 31 a 50) también el sexo femenino tuvo mayor incidencia respecto al masculino; sin embargo en el rango etario de $5 \mathrm{I}$ a 75 años existió una diferencia mínima entre el sexo masculino (4\%) y el sexo femenino (3\%).

- Las piezas dentarias más afectadas con la patología de necrosis pulpar fueron el incisivo central superior, el incisivo lateral superior y el primer premolar superior respectivamente.

- El diagnóstico clínico que más incidencia tuvo del total de los casos analizados fue el de necrosis ylo gangrena pulpar con signos radiográficos de normalidad en la zona periapical, siguiendo en orden de incidencia el diagnóstico de necrosis ylo gangrena pulpar con proceso periapical y luego el diagnóstico de necrosis y/o gangrena con ensanchamiento periodontal.

- Se pudo comprobar que hubo relación estadísticamente significativa $(p<0.05)$ en cuanto a la localización de la afección, diagnóstico y sexo.

\section{Bibliografia}

I. Ingle Jl, Bakland LK. Patología Pulpar: Etiologia y Prevención. En Ingle Jl, editor del libro. Endodoncia. 5a Ed. México: Mc Graw- Hill Interamericana; 2003. p. 95 - 169.

2. Queralt R, Durán-Sindreu F, Ribot J, Roig M. Manual de Endodoncia. Parte 4. Patología pulpo-periapical. Rev Oper Dent Endod. 2006; 5: 24.

3. Kustner Chimenos Eduardo. "Radiologia en Medicina Bucal". Barcelona España: Masson; 2005.

4. Mautino Chang-Navarro Luz. "interpretación radiográfica de enfermedades pulpares en dientes deciduos y permanentes". Universidad nacional mayor de san marcos. Facultad de Odontologia. Lima- Perú 2008.

5. Nair P.N.R. Fisiopatología de la periodontitis apical primaria. En Stephen Cohen, Kennhet M. Hargreaves. Vias de la pulpa. 9na ed. Ed. Madrid- España: Elsevier; 2008. P. 55। $-89$. 
Gráfico 2: Incidencia según localización y diagnóstico: sexo femenino .Cátedra Endodoncia. Facultad de Odontología. Universidad Nacional del Nordeste. Año 2005-2007

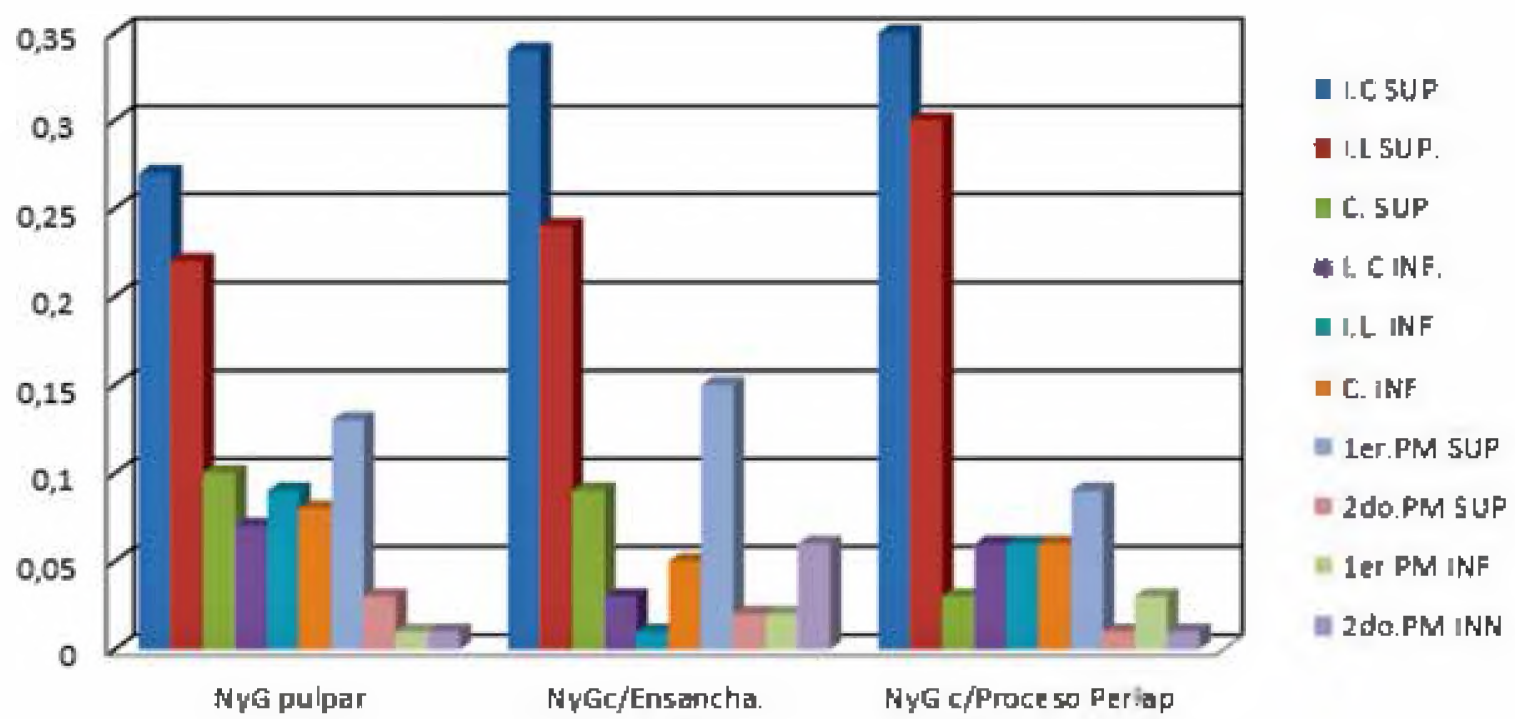

Gráfico 3: Incidencia según localización y diagnóstico: sexo masculino. Cátedra Endodoncia. Facultad de Odontología. Universidad Nacional del Nordeste. Afío 2005-2007.

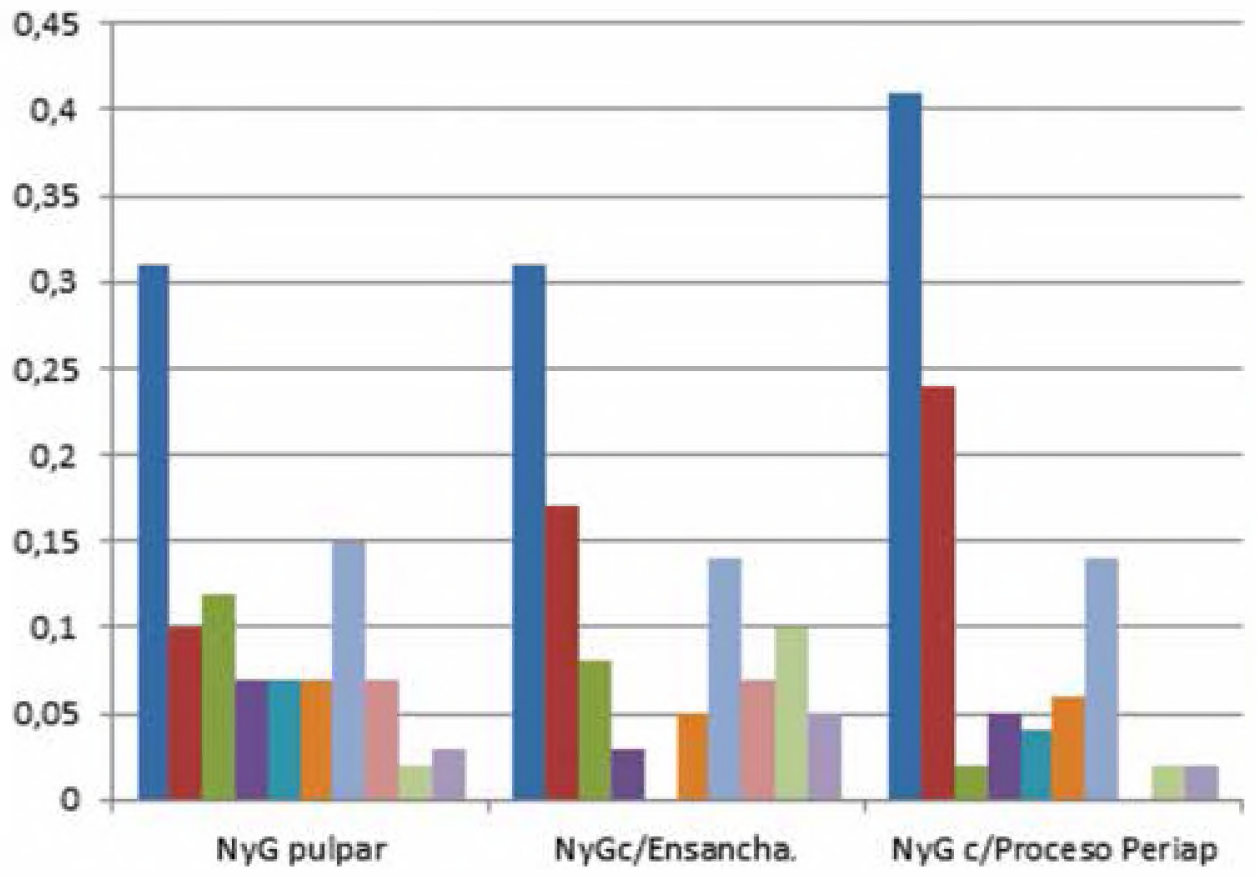


6. Ferro Benítez, Pedro Pablo, Quiñones Ybarría Maria Elena, Espinosa González Leticia, Felipe Torres Sonia, Salamanca Villazón Ledia. Tratamiento no quirúrgico de lesiones periapicales. Rev Cubana Estomatol 2005 Ago [citado 20II Mar 29]; 42(2).Disponible en: http://scielo.sld.cul scielo.php?script=sci_arttext\&pid=S003475072005000200008\&lng=es.

7. Padilla Alejandro R., Ruprecht Axel "Estudio radiográfico de las infecciones de los maxilares". Disponible en: http://issuu.com/ padilla4/docs/interpretacion_radiografica.

8. Reit, Claes, Hollender Lars. "Radiografic evaluation of endodontic therapy and the influence of observer variation". Rev. Scand. J. Dent. Res., 1983; 91: 205 - 12.

9. Gutmann JL, Dumsha TC, Lovdahl PE. "Solución de problemas en Endodoncia. Prevención, identificación y tratamiento". 4ta ed. Madrid- España: Elsevier; 2007.

10. Strindberg L. "The dependence of the results of pulp therapy on certain factors: an analytic study based on radiographic and clinical follow-up examinations". Acta Odontol Scand 1956; I 4 (supple 2 I): I- I 75.

II. Gelfand M., Sunderman E. J., Goldman M. "Reliability of radiographical interpretations". J. of Endod. Feb. I 983; 9 (2): 7I - 75.

12. Haugejorden O., Slack G.L. A study of intraexaminer error associated with recording of radiographic caries at different diagnostic levels. Acta odontol Scand 1975; 33: $169-8 \mid$.

13. Gröndahl H.G. "Radiographic caries diag- nosis. A study of caries progression and observer performance" . Swed Dent J. 1979; suppl 3.

14. Finten Susana B., Testi J. A., Rusas M. G., Costa R. S. "2580 Tratamientos Endodónticos: su evaluación radiográfica". Rev. de la Facultad de Odontología de la U.N.N.E. $N^{\circ} 21$. Año 2003.Pruskin Elena, Hilú R.E, Mellado A.S. "Analisis de los tratamientos endodónticos realizados en la clínica asistencial y de capacitación (CAYC)" .Rev. Asoc. Odontologica Argentina. Enero/ febrero 1999; 87 (I): 30 - 33.

15. Farrel T. H., Burque F. J. "Root canal treatment in the General Dental Service 1984-1987". British Dental Journal 1989; 166 - 203.

16. Marsilly Perdomo X., Moncada Ortiz C., La O Salas N.O., Carpio Corona H.M., Betancourt L.E. "Principales aspectos clínicos de las afecciones endoperiodontales". Medisan 2006; 10 (I). Disponible en: http:// www.bsv.sld.cu/revistas/san/vol I0_I_06/ san07I06.

17. Björn Ödesjö y cols. "Prevalence of previous endodontic treatment, technical standard and occurrence of periapical lesions in a randomly selected adult, general population". Endod Dent Traumatol 1990; 6: 265 - 272.

18. Lorena Lafuente Taborga. "Piezas anteriores con presencia de Procesos Periapicales en pacientes que acudieron a la clínica odontológica en 2005". Universidad privada del valle. Bolivia; 2005. 